\title{
Institutional Insights for Analysing Strategic Manoeuvring in the British Prime Minister's Question Time
}

\author{
Dima Mohammed
}

Published online: 11 April 2008

(C) The Author(s) 2008

\begin{abstract}
This paper aims at creating an adequate theoretical basis for a systematic integration of institutional insights into the pragma-dialectical analysis of argumentative exchanges that occur in institutionalised contexts. The argumentative practice of Prime Minister's Question Time in the British House of Commons is examined, as a case in point, in order to illustrate how the knowledge of the characteristics of an institution, its rules and conventions can be integrated into the pragma-dialectical analysis. The paper highlights the role that theoretical concepts and tools such as strategic manoeuvring, argumentative activity types and dialectical profiles play in this integration.
\end{abstract}

Keywords Argumentative activity type - Dialectical profile ·

Institutionalised argumentative practice · Prime Minister's Question Time ·

Strategic manoeuvring

\section{Introduction}

The knowledge of the characteristics of the institutionalised contexts in which argumentative exchanges occur provides significant insights for the examination of these exchanges. This paper focuses on the institutionalised aspects of argumentative discourse in light of the pragma-dialectical (van Eemeren and Grootendorst 1984, 2004; van Eemeren and Houtlosser 2003, 2007c) pursuit of a more empirically adequate account of argumentative practice. An important step in this pursuit is the introduction of the concept of argumentative activity types

D. Mohammed $(\bowtie)$

Department of Speech Communication, Argumentation Theory and Rhetoric, University

of Amsterdam, Spuistraat 134, 1012 VB Amsterdam, The Netherlands

e-mail: d.mohammed@uva.nl 
(van Eemeren and Houtlosser 2005). ${ }^{1}$ After accounting for the arguers' empirical concern of persuasiveness, through the concept of strategic manoeuvring (van Eemeren and Houtlosser 1999, 2007b), the concept of argumentative activity types has been introduced in order to account for the institutionalised aspects of argumentative practice (van Eemeren and Houtlosser 2007a). Activity types characterise types of argumentative discourse by situating argumentative exchanges in their specific more or less formal institutionalised contexts. Such a characterisation is essential, given that the features of such contexts provide opportunities and impose constraints on the production of argumentative discourse.

The integration of institutional insights into the pragma-dialectical framework is beneficial to both the framework and the institutionalised argumentative practice concerned. The integration makes the framework more suitable for examining argumentative practices; it allows for taking the characteristics of institutional contexts into account, leading to a more empirically adequate and critically insightful examination of argumentative exchanges. Such an examination has the potential to improve the examined practice, as it highlights the potential link between critical reasonableness and institutional effectiveness of an institutionalised argumentative practice. In this paper, I aim at creating an adequate theoretical basis for a systematic integration of institutional insights into the pragma-dialectical method. For that purpose, I shall discuss the theoretical concepts of strategic manoeuvring, argumentative activity types and dialectical profiles in light of their contribution to the promoted integration. A case in point for illustrating the merits of such integration will be Prime Minister's Question Time in the British House of Commons.

\section{Merits for Integrating Institutional Insights into the Pragma-Dialectical Approach}

The more empirically adequate account of institutionalised argumentative practice, as a result of the integration of institutional insights into the pragma-dialectical framework, sets the ground for a critically insightful examination that is beneficial for the institution concerned. In institutions where institutional aims are achieved through argumentative exchanges, it seems sensible to assume that the critical testing of points of view through argumentation is instrumental (or even crucial) to the achievement of institutional aims. That makes the results of the pragmadialectical examination of the critical reasonableness of institutionalised argumentative exchanges highly indicative of the quality of the institutional procedures. To illustrate this point, let us examine the argumentative practice of Prime Minister's Question Time in the British House of Commons as an example of an institutionalised argumentative practice, the examination of which within a

\footnotetext{
${ }^{1}$ Similar to Levinson's concept of activity type $(1979,1992)$, the pragma-dialectical argumentative activity types are aim-driven, and with structural elements that are rationally and functionally adapted to the aim of the activity. In contrast to Levinson's, the pragma-dialectical activity types refer only to those activities in which argumentation plays a central role. As van Eemeren and Houtlosser describe them, the pragma-dialectical argumentative activity types refer to 'cultural artefacts [within argumentative discourse] that can be identified on the basis of careful empirical observation of argumentative practice' (2005).
} 
pragma-dialectical framework is indicative of the success or failure of the argumentative exchanges to achieve the institutional aims they are supposed to promote.

Prime Minister's Question Time in the British House of Commons is the weekly session in the Parliament of the United Kingdom in which the Prime Minister provides oral answers to the questions of his fellow Members of Parliament. The aim of the session is to hold the government to account (House of Commons Information Office 2005; Rogers and Walter 2006). This aim is realised through question-answer exchanges pertaining to issues that fall under the responsibility of the Prime Minister as the head of government. Even though, on the surface, Question Time seems to be an information-seeking session, it is in fact an argumentative political exchange that constitutes a mini-debate over the performance of the government (Wilson 1990; Beard 2000; House of Commons Information Office 2005; Rogers and Walter 2006).

The performance of the government is controversial: while the Prime Minister and the government's ministers are in favour of a positive evaluation of the performance of the government, the opposition Members of Parliament are at least challenging this positive evaluation, but are also often in favour of a negative evaluation. ${ }^{2}$ It is precisely this controversy that lies behind question-answer exchanges in Question Time. As the Members of Parliament and the Prime Minister exchange questions and answers concerning the plans and policies of the government, they, in fact, express and defend their points of view in this controversy. It is through the discussion of the different points of view adopted by Members of Parliament in this controversy that the institutional aim of Question Time is achieved. The argumentative exchanges concerning the policies, plans and actions of the government provide a continuous evaluation of the performance of the government; the government's performance is kept under scrutiny as the means to hold it to account. Ideally, the argumentative discussion of the plans, policies and actions of the government needs to be governed by the norm of critical testing. In reality, however, the more argumentative exchanges comply with the norm of critical testing, as a means to scrutinise the performance of the government, the more the government is subject to scrutiny, and the better it is held to account. The norm of critical testing can-in that sense- - be regarded instrumental to the achievement of institutional aims, and the assessment of the critical reasonableness of the argumentative exchanges can be indicative of the extent to which the institutional aims of such exchanges are achieved.

\section{Argumentative Activity Types and the Analysis of Institutionalised Argumentative Exchanges}

The characterisation of institutionalised argumentative practices as argumentative activity types provides necessary general guidance for the reconstruction of

\footnotetext{
${ }^{2}$ Usually the Members of Parliament from the ruling party are also in favour of a positive evaluation of the government. However, in contrast to the Prime Minister and the government's ministers-who have the parliamentary obligation to justify the performance of the government- the Members of Parliament from the ruling party are 'free' to adopt the position they choose. Their conventional support for the government is in fact based on a party-related obligation, and so is the opposition's conventional challenge.
} 
institutionalised argumentative exchanges in terms of a critical discussion, as the first step in a pragma-dialectical analysis and evaluation. Based on a careful examination, the institutionalised argumentative practice is characterised in terms of four elements that correspond to the four stages of a critical discussion. The practice is characterised in terms of its initial situation, starting points, argumentative means and the way in which the outcome is determined, in parallel to the confrontation, opening, argumentation and concluding stages of a critical discussion respectively (van Eemeren and Houtlosser 2005). Even though the characterisation is intended, mainly, to assist the analysis of argumentative practices that occur in institutionalised contexts, the characterisation has also the advantage of putting the pragma-dialectical analysis and evaluation of institutionalised argumentative practice in perspective. A proper characterisation highlights the merits of a pragma-dialectical examination of the institutionalised conventional practice, by emphasising the instrumentality of the critical testing procedure to the achievement of institutional aims.

Prior to the characterisation of an institutionalised argumentative practice as activity types, it is useful to define the activity type concerned. A proper definition of an activity types needs to define the institutionalised argumentative practice in terms of three main elements: the initial difference of opinion, the institutional aim and the way in which the resolution of the initial difference of opinion contributes to the achievement of institutional aims. For example, the argumentative practice in Prime Minister's Question Time in the British House of Commons can be defined as:

the argumentative activity that starts from a difference of opinion concerning the performance of the government, and aims at holding the government to account, through continuous argumentative discussions of its plans, policies and actions.

The definition of an activity type is important. Not only does it highlight the instrumentality of critical testing to the achievement of institutional aims, but it also clearly defines the subject of the intended pragma-dialectical examination as those argumentative exchanges that occur as part of an institutional practice. The latter is vital as it eliminates the confusion that could result from mistaking the activity type to describe the whole institutional practice of an institution.

Following the definition, and based on a careful examination of the argumentative practice of Question Time, this activity type can be characterised in terms of the four stages of a critical discussion. The initial situation of Question Time can be characterised as a mixed difference of opinion concerning a proposition evaluating the performance of the government, for example, that the government's performance is up to standard. As starting points, Question Time has clear procedural rules and assignment of roles. The rules of Question Time make it clear that the Prime Minister is the main protagonist of the positive standpoint, since he is expected to always defend his government. The Members of Parliament from the Opposition and the leader of the Opposition in particular are conventionally the protagonists of the negative standpoint. The rules and conventions of Parliament make it also clear what kinds of contributions are allowable: the Members of Parliament pose questions and the Prime Minister provides answer. Furthermore, questions must conform to Parliamentary conventions regarding Parliamentary 
language and respect for the Crown, the judiciary and Members of the two Houses of Parliament. Questions must always relate to a matter for which the Prime Minister is responsible, as the head of government; they may not, for example, touch on activities in his capacity as a party leader or member.

The argumentative means allowed for the parties are also determined by the rules and conventions of Question Time. In Question Time, the Members of Parliament need to advance their argumentation in the form of a question, and the Prime Minister should formulate his argumentation in the form of an answer. Every question posed by a Member of Parliament usually advances an implicit argument in support of either a positive or a negative point of view in relation to the proposition the performance of the government is up to standard. The implicit arguments advanced by the Members of Parliament need to relate to the plans, policies and actions of the government. Conventionally, Members of Parliament anticipate that their arguments are faced by, at least, doubt, and argue in support of them. Consequently, every question provides not only an argument in support of the main (positive or negative) standpoint, but also constitutes the initiation of a subdiscussion concerning the evaluation of a certain plan, policy or action of the government. In other words, every question advances a sub-standpoint, in which an attitude either in favour or against a certain plan, policy or action of the government is expressed. Together with the answer that follows, the question constitutes a subdiscussion pertaining to the sub-standpoint advanced as an argument in defence of the main standpoint. At the end of the argumentative discussion in Question Time, it is to be determined whether the difference of opinion concerning the main standpoints is resolved; usually however, the resolution remains implicit. ${ }^{3}$

The example below illustrates how the characterisation of the activity type of Question Time provides guidance for the reconstruction of argumentative exchanges that occur in it.

\section{Mr. David Cameron, the leader of Opposition:}

So the flagship of forced mergers has sunk without trace. Let us turn to another flagship that is sinking fast-ID cards. Will the Prime Minister admit to the House that the whole project is now being reviewed, including the timetable and the type of card?

\section{Mr. Tony Blair, the Prime Minister:}

No, I certainly will not say that, because it is not correct. It is very important[Interruption.] If the right hon. Gentleman is basing his comments on leaked emails in the newspapers, I suggest that he does not raise that topic. If he looks at what is happening, he will see that it is important that we proceed with identity cards for the simple reason that if we do not have a proper identity card system, we will not be able to track illegal immigrants in this country or prevent identity fraud and abuse. It is for that reason that we most certainly will proceed to introduce identity cards.

(Parliamentary Archives 2006)

\footnotetext{
${ }^{3}$ For an elaborate discussion of the Prime Minister's Question Time as an argumentative activity type, see Mohammed (2007).
} 
In this exchange, the leader of the opposition asks the Prime Minister a question about the government's identity cards plan, implying and trying to make the Prime Minister admit that the ID cards plan is a failure. In light of the proposed characterisation of the activity type of Question Time, the argumentative exchange can be reconstructed as a mixed dispute over the proposition the performance of the government is up to standard. In relation to this proposition, two main standpoints, a positive and a negative one, can be identified. Mr. Blair, the Prime Minister, is the protagonist of the positive standpoint that the performance of the government is up to standard, and Mr. Cameron, the leader of Opposition, is the protagonist of the negative standpoint that the performance of the government is not up to standard. Both standpoints are left implicit. In this specific exchange, Mr. Cameron's main argument is implied in the question he asks: the identity cards plan of the government is a failure. Similarly, Mr. Blair's main argument is implied in his answer, as he argues that the concerned plan is not a failure, and that it rather necessary. The following is the analytic overview of the exchange, in which the subdiscussion is clear.

Mr. Cameron's argumentation can be reconstructed as follows:

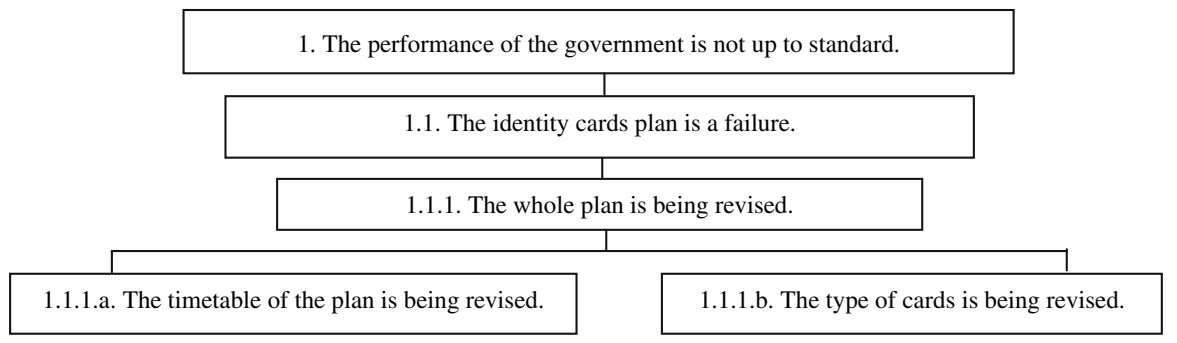

In response, the Prime Minister's argumentation can be reconstructed as follows:

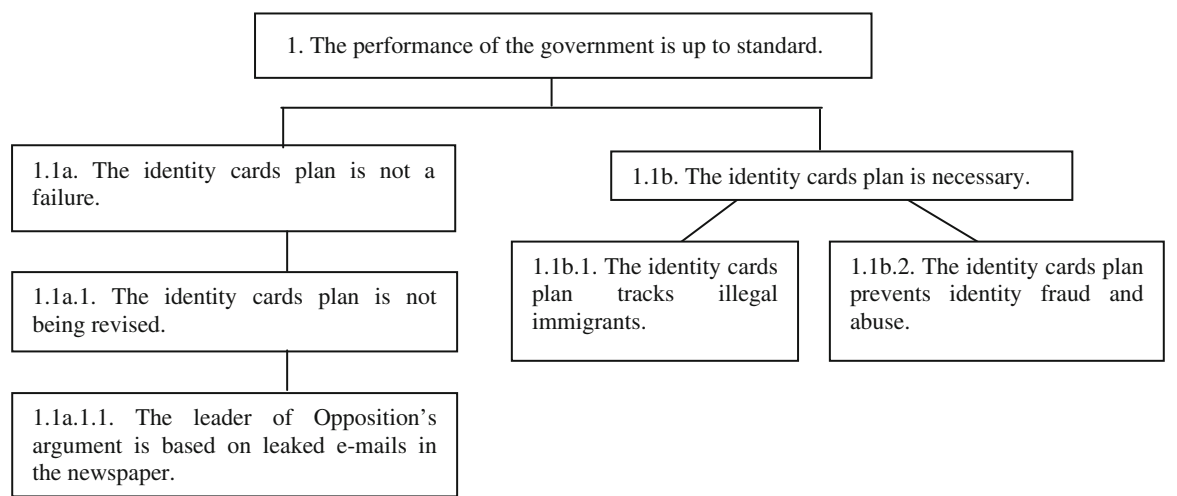

As it can be seen from the analytic overview, a sub-discussion has been initiated by the question asked by the Mr. Cameron. The sub-discussion is about his main argument that the ID cards plan is a failure. The sub-dispute is mixed, since the Prime Minister, as expected from him, rejects the sub-standpoint and adopts its opposite. 
A proper characterisation of the activity type should not only facilitate the reconstruction of argumentative exchanges, but also reconcile institutional rules and conventions with the pragma-dialectical rules for reasonable discussants. ${ }^{4}$ For example, the rules of Question Time which stipulate that the Members of Parliament are allowed to ask questions that pertain only to the responsibilities of the Prime Minister as head of government seem to obstruct the process of critical testing as they restrict the discussants' freedom of advancing their points of view. Such obstruction is viewed in the pragma-dialectical approach as a violation of the first rule of a critical discussion (the freedom rule), which stipulates that "discussants may not prevent each other from advancing standpoints or from calling standpoints into question" (van Eemeren and Grootendorst 2004, p. 190). However, a closer examination of the argumentative practice, in light of the characterisation of the activity type, reveals that the restriction of this rule applies, in fact, not to the propositional content of the discussants' standpoints but to the propositional content of their arguments instead. As we have come to see through the characterisation of the activity type, the questions that the Members of Parliament pose imply, in effect, their arguments in support of the main standpoint, which expresses either a negative or a positive evaluation of the performance of the government. In light of this view, the restriction imposed by the institutional rules is no longer an obstruction to critical testing. It is, rather, a specification of the fourth rule of a critical discussion (the relevance rule). According to the relevance rule, the discussants need to defend their standpoints by using argumentation that is relevant to the standpoint at stake. Rule four of the code of conduct for reasonable discussants stipulates that "standpoints may not be defended by non-argumentation or argumentation that is not relevant to the standpoint" (van Eemeren and Grootendorst 2004, p. 192).

The institutional rule that restricts the topic of the questions asked by Members of Parliament to those issues for which the Prime Minister is responsible eventually specifies what counts as relevant argumentation in support of the standpoint in the specific context of the institution of Question Time. Rightly, what is relevant for the evaluation of the performance of the government are the issues that fall under the responsibility of the Prime Minister.

\section{Institutional Insights for the Analysis of Strategic Manoeuvring}

While the characterisation of institutionalised argumentative practices as argumentative activity types primarily guides the analyst in analysing institutionalised argumentative exchanges in terms of a critical discussion, such characterisation also provides assistance in analysing the moves that occur as part of these exchanges. As

\footnotetext{
${ }^{4}$ Ideally, as a result of the instrumentality of argumentation to the achievement of institutional aims, institutional rules and conventions need to be in adherence with the norm of critical testing. Institutional rules and conventions are supposed to promote the achievement of institutional aims; since in institutions where argumentation plays a central role, these aims are achieved through argumentation, institutional rules and conventions need to ensure that reasonable argumentation is not obstructed. However, in practice, some institutional rules or conventions might constitute an obstruction to the procedure of critical testing. The examination of such obstructions can be helpful in the evaluation of the efficiency of institutional procedures in promoting institutional aims. The examination can also be useful for the evaluation of such procedures in order to improve their efficiency.
} 
van Eemeren and Houtlosser (2007a, p. 376) put it, "depending on the activity type and the prevailing conventional preconditions, different constraints apply with regard to the strategic manoeuvring that is allowed".

In light of the concept of strategic manoeuvring, every move in argumentative practice is an instance of strategic manoeuvring in which a certain choice of topics, audience frames and stylistic presentational devices is made (van Eemeren and Houtlosser 2002). The knowledge of the rules and conventions of a certain institution provides significant insights for understanding the arguer's choice. The understanding is further enhanced by the knowledge of the role that a certain move fulfils in the context of critical testing, which can be derived from dialectical profiles.

\subsection{Dialectical Profiles and the Distinction Between Concrete and Analytically Relevant Moves}

In the pragma-dialectical approach to argumentation, real argumentative exchanges are examined in terms of the ideal model of a critical discussion. The ideal model, which prescribes the procedure for a critical resolution of differences of opinion, specifies the moves that the arguers would have to perform if they were aiming solely at critically resolving their difference of opinion (van Eemeren and Grootendorst 2004). Real argumentative discussions, however, do not usually proceed in the way prescribed in the ideal procedure, if only because discussants almost never aim only at the critical resolution of their differences of opinion. In real argumentative exchanges, discussants engage in (actual) procedures that are derived from the different contexts in which their argumentative exchanges take place. Actual argumentative exchanges that occur in institutionalised contexts, for example, follow an institutional procedure that is governed by institutional rules and conventions and is aimed at the achievement of an institutional aim. When examining such exchanges within a pragma-dialectical framework, such procedures are reconstructed in light of the ideal procedure of critical testing as a necessary step for the assessment of the reasonableness of argumentation (van Eemeren et al. 1993). In the case of Prime Minister's Question Time, for instance, the argumentative exchange of the Members of Parliament and the Prime Minister follows the institutional procedure of question-answer, which is governed by the rules and conventions of Question Time, and aimed at holding the government to account. As I have argued earlier, these exchanges are reconstructed in light of the procedure of critical resolution as a critical discussion about the performance of the government.

Moving from the level of argumentative exchanges to the level of argumentative moves, a distinction can be made between analytically relevant moves (van Eemeren and Grootendorst 1992) and the moves that arguers actually perform in real argumentative exchanges. Analytically relevant moves are those moves that are potentially relevant to the resolution of the difference of opinion, i.e. they, in principle, can be assumed to play a role in the ideal procedure of critical resolution. In contrast, argumentative moves that arguers in real argumentative exchanges perform, hereafter referred to as concrete argumentative moves, are part of an actual procedure. For example, the move of advancing a standpoint is an analytically relevant move in the domain of the confrontation stage of a critical discussion. However, in the course of the actual discussion in Prime Minister's Question Time, for example, the move of asking 
the Prime Minister a question is the corresponding concrete argumentative move. The concrete move, of a question in this case, is actually performed by the discussant; it comes as part of the institutional procedure of question-answer exchanges.

The analytically relevant moves in a particular discussion stage are those represented in the dialectical profile of the stage (van Eemeren et al. 2007a, b). Dialectical profiles represent, in dialogical trees, all the options for making analytically relevant moves that the parties of a dispute have in the course of a particular stage of the critical testing procedure. Below, for example, is the dialectical profile for the confrontation stage of a potential mixed dispute. The profile specifies the dialectical moves that are analytically relevant to the achievement of the dialectical goal of the confrontation stage. In order to successfully define the type of dispute that is to be resolved through the course of the discussion, the parties in a critical discussion need to perform only those types of moves that are represented in the profile.

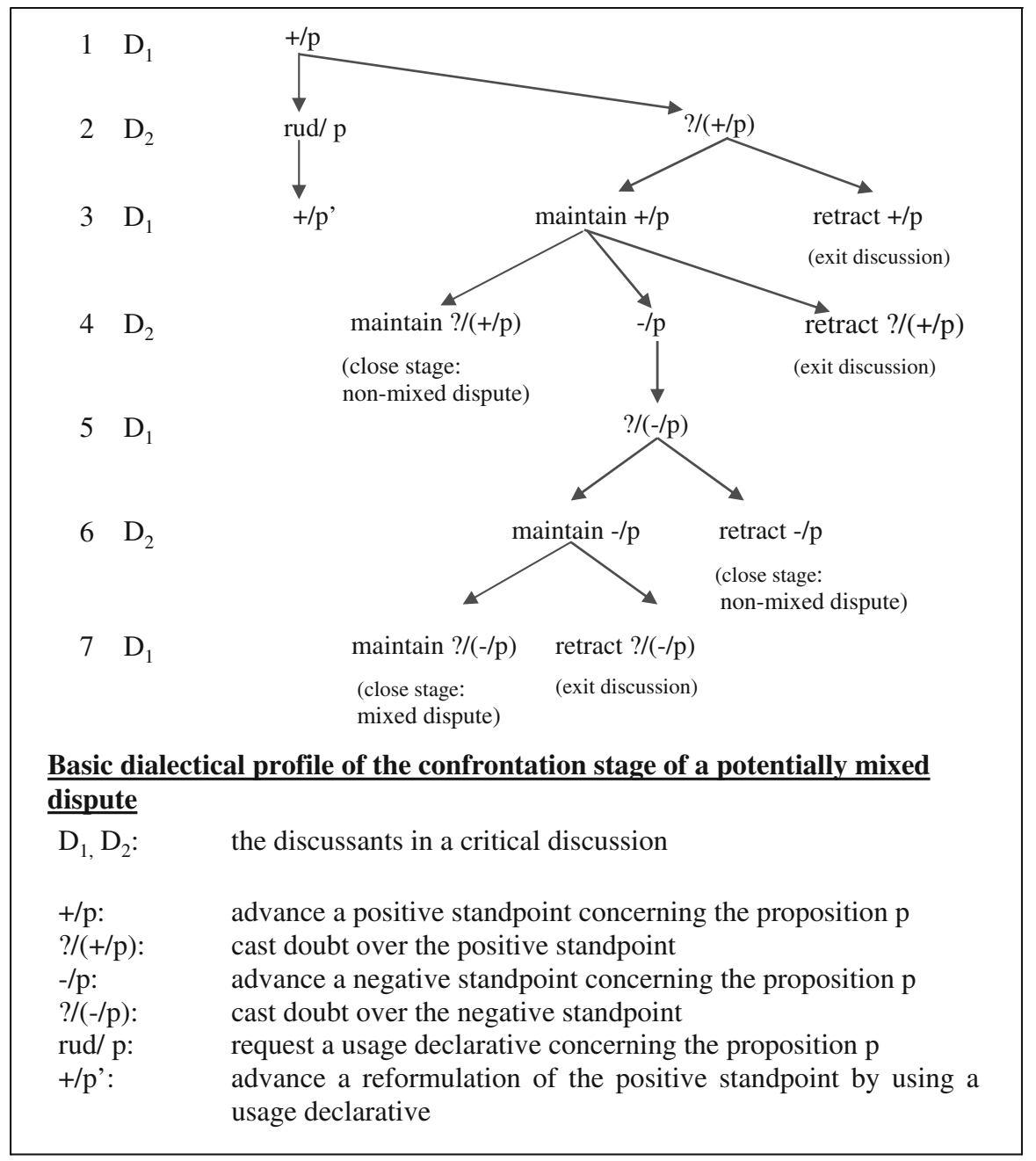


The main advantage of using dialectical profiles in the analysis of argumentative practice is that the profiles bridge the gap between the model of a critical discussion as an ideal for argumentative discourse and the less than ideal argumentative practices. When argumentative exchanges are reconstructed as a critical discussion, concrete argumentative moves from argumentative practice are to be reconstructed into the analytically relevant moves that makes their argumentative function explicit. The profile generates a finite list of all the moves that are analytically relevant to the resolution of a difference of opinion, into which concrete speech acts need to be reconstructed. In that sense, every concrete speech act that is performed in the course of an argumentative exchange has an analytically relevant move that represents it in the dialectical profile of the pertinent stage of a critical discussion. While the moves in the dialectical profile, being derived from the ideal model of a critical discussion, are potentially sound, they can yet be used to represent fallacious concrete argumentative moves.

\subsection{Institutional Rules and Conventions and Strategic Manoeuvring}

A concrete argumentative move in an actual argumentative exchange is the realisation of an analytically relevant move in a dialectical profile. In fact, every analytically relevant move in a dialectical profile represents a slot that can be realised in actual argumentative exchanges in more than one way. For example, a question that a Member of Parliament poses can be the realisation of the analytically relevant move of advancing a positive standpoint, and so can the statement through which a Member of Parliament introduces his question. ${ }^{5}$ Given that in light of the concept of strategic manoeuvring, every concrete argumentative move is considered an instance of strategic manoeuvring, instances of strategic manoeuvring can be viewed as realisations of analytically relevant moves. In every move they make, arguers strategically manoeuvre attempting to maintain a balance between their dialectical aim of being reasonable and their rhetorical aim of being persuasive; the arguers' choice of the topics of their arguments, the way to frame the perspective of the audience and to exploit the appropriate stylistic means to present them is governed by this attempt (van Eemeren and Houtlosser 2002).

As arguers advance concrete argumentative moves in the context of an institutionalised argumentative practice, the three aspects of strategic manoeuvring get restricted by the rules and conventions of the institution concerned. Institutional rules and conventions regulate concrete institutional procedures. They specify what the allowable concrete moves in such procedures are, and influence the arguer's strategic manoeuvring in performing the concrete argumentative moves advanced as part of such procedures, accordingly. In that sense, the rules and conventions of an institution specify what the institutionally relevant moves are. They do so by restricting the topic, the adaptation to the audience perspective and the presentation

\footnotetext{
${ }^{5}$ Not only can a single analytically relevant move from the profile be realised by a multitude of types of concrete argumentative moves, but one single analytically relevant move can also eventually be realised by more than one concrete argumentative move in the discourse. For example, the analytically relevant move of casting doubt can be realised by a series of concrete moves in which an arguer accuses another of being inconsistent implying challenge to his point of view.
} 
of the moves that discussants are allowed to perform in the course of the institutional procedure. For example, the rules and conventions of Question Time restrict the presentation of the allowable moves to questions by the Members of Parliament, and answers by the Prime Minister. The rules and conventions further restrict the topic of the questions that the Members of Parliament are allowed to ask, as they stipulate that the Members of Parliament need to address in the questions they pose to the Prime Minister issues that are relevant to the responsibilities of his government.

The restrictions imposed by institutional rules and conventions on the performance of concrete speech acts, can be viewed as restrictions applied to the possible realisations of the slots of analytically relevant moves from the dialectical profile. In a way, institutional rules and conventions specify what instances of strategic manoeuvring can be considered as institutionally relevant realisations of analytically relevant moves. Institutional rules and conventions restrict the range of choice for what counts as institutionally relevant moves, in the three aspects of strategic manoeuvring. For example, in relation to the analytically relevant move of advancing an argument in support of the main standpoint, institutional rules and conventions stipulate that its institutionally relevant realisations need to relate to a topic that falls under the responsibility of the government, address the Speaker of the House and be presented in the form of a question. ${ }^{6}$

\section{Analysing Strategic Manoeuvring in the Context of Prime Minister's Question Time: The Case of Inconsistency Regarding Darfur}

In order to illustrate the role that institutional insights can play in the analysis of argumentative moves, I shall examine the exchange below, from Prime Minister's Question Time of 13 June 2007, in which, the Member of Parliament, Mr. Shailesh Vara, from the Conservative Party asks the Prime Minister, Mr. Tony Blair, about the actions of the government regarding the crisis in Darfur.

\section{Mr. Shailesh Vara:}

Does the Prime Minister believe that it is right that, on the one hand, he and his Government should be critical of the Sudanese regime's butchery in Darfur, yet on the other hand, at British military establishments, Sudanese military personnel received training as recently as April this year?

\section{Mr. Tony Blair, the Prime Minister:}

I would have to look into that fairly carefully before I agreed with the premise behind the hon. Gentleman's question, if I may say so. As far as I am aware,

\footnotetext{
${ }^{6}$ Even though the allowable contributions for the Members of Parliament are restricted to questions, Members of Parliament do perform other types of speech acts indirectly. For example, Members of Parliament can perform the speech act of accusations of inconsistency, indirectly in the questions they pose. Both the direct and indirect speech acts are nevertheless part of an actual argumentative exchange.
} 
any training that we give to the military of whatever country is training that also upholds respect for law and order, human rights and so on. I simply do not know about the particular instance that the hon. Gentleman mentions, but let me tell him that we are continuing to put all the pressure we can on the Sudanese Government to come into compliance with the international community's recommendations, and over the next couple of weeks, if there is not action by the Sudanese Government, we will be tabling a United Nations Security Council resolution.

(Parliamentary Archives 2007)

In this question, the Member of Parliament from the Conservative Party asks the Prime Minister to justify the government's position in light of a charge of inconsistency: while the government is expressing criticism towards the Sudanese regime's actions in Darfur, it provides training for the Sudanese military who are involved in them. In response, the Prime Minister attempts to deny the charge of inconsistency. While he admits the alleged critical attitude towards the Sudanese government, he denies having knowledge of the particular example of the alleged support which the Member of Parliament refers to. Nevertheless, the Prime Minister defends the government's action as he argues that if such training has happened, it would surely 'uphold respect for law and order and human rights', as this is the case for all trainings provided by the British military establishment to foreign military. The Prime Minister goes further expressing and defending the government's commitment to the alleged critical attitude towards the Sudanese government.

In light of the characterisation of the activity type of Question Time, presented in the second section, above, the question-answer exchange can be viewed as part of mixed dispute over the performance of the government. The Member of Parliament is of the point of view that the performance of the government is not up to standard, and the Prime Minister is in favour of the opposite point of view, mainly that the performance of the government is up to standard. In defending his point of view, the Member of Parliament argues that the actions of the government in relation to Darfur are not acceptable and provides the example of the training that has been provided to the Sudanese military by the British establishment no longer than 2 months ago. The Member of Parliament further employs an accusation of inconsistency in an attempt to make the expected justification of the training by the Prime Minister almost impossible, as it would be hard for the Prime Minister to justify actions which are in contradiction with the government's own-rightly expressed-stance of criticism towards the butchery in Darfur. The Prime Minister's response tackles the same argument that the Member of Parliament presents (that the government's actions in relation to Darfur are unacceptable): he first denies knowledge of the alleged training as an instance of these actions, and then attempts to justify it - if it has happened - as being acceptable, because it is legal and upholds respect for human rights. Following is the analytic overview of the argumentation advanced by the Member of Parliament and the Prime Minister, respectively: 
(a)

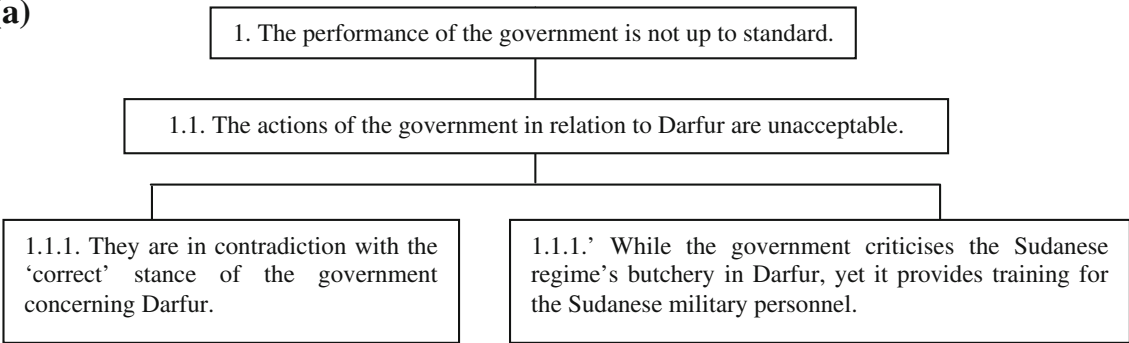

(b)

1. The performance of the government is up to standard.

1.1. The actions of the government in relation to Darfur are not unacceptable.

1.1.1a. It is not sure the British establishment has provided training for Sudanese military personnel. 1.1.1b. A possible training for the Sudanese military is not necessarily in contradiction with the 'correct' stance of the government concerning Darfur.

1.1.1b.1. The training provided by the British establishment to foreign military is always legal and upholds respect for human rights.

The exchange at hand constitutes eventually a sub-discussion concerning the argument that the actions of the government in relation to Darfur are unacceptable. In this analysis, I would like to focus on the accusation of inconsistency employed by the Member of Parliament in support of his point of view, in the course of this sub-discussion. As an argumentative move, the accusation above will be discussed as an instance of strategic manoeuvring, in the course of the argumentative exchange concerning the argument of the Member of Parliament that the actions of the government in relation to Darfur are unacceptable.

The dialectical profile of the confrontation stage provides useful insights for understanding what the Member of Parliament is trying to do argumentatively with the advanced accusation of inconsistency. In the context of Question Time, the dialectical profile of the confrontation stage can be used to examine the argumentative confrontations of the sub-discussions that are initiated when Members of Parliament anticipate doubt towards the arguments that they advance in support of the main standpoint. The anticipation of doubt, as argued earlier, turns the arguments into sub-standpoints. In the discussion of these sub-standpoints, Members of Parliament perform concrete speech acts that can be represented by one of the following analytically relevant moves: advancing a sub-standpoint (turn 1, in the profile), providing a usage declarative (turn 3 , in the profile), maintaining or retracting the advanced sub-standpoint (turn 3, in the profile), casting doubt over the opposite sub-standpoint (in turn 5, in the profile, once this opposite sub-standpoint 
has been advanced) and either maintain or retract the latter doubt (turn 7, in the profile). Similarly, in the same discussion, the Prime Minister performs concrete speech acts that need to be reconstructed as one of the following analytically relevant moves: request for usage declarative (turn 2, in the profile), casting doubt (turn 2, in the profile), maintaining or retracting doubt as well as advancing the opposite sub-standpoint (turn 4 , in the profile), and finally maintaining or retracting the advanced opposite sub-standpoint (turn 6, in the profile).

In the exchange at hand, the accusation of inconsistency can be reconstructed as the analytically relevant move of maintaining a positive sub-standpoint performed by discussant 1 at the third turn in the dialectical profile of the confrontation stage. This accusation is an instantiation of the analytically relevant move of maintaining a positive sub-standpoint, through which discussant 1 attempts to make discussant 2 retract his doubt concerning the sub-standpoint advanced by discussant 1 . The accusation is therefore an instance of strategic manoeuvring that aims at making the opponent retract his doubt in the course of the argumentative confrontation. In the exchange at hand, the Member of Parliament accuses the Prime Minister and the government of an inconsistency between their words and deeds: while the government's stance is critical to the Sudanese military, its deeds are supportive. Employing this accusation of inconsistency, the Member of Parliament attempts to get the Prime Minister to admit that either of the two (i.e. words or deeds) is unacceptable; in this case, Mr. Vara wants the Prime Minister to admit that the government's actions are unacceptable, as this is in fact his own sub-standpoint. If he admits that, Mr. Blair has to retract his doubt concerning the sub-standpoint of Mr. Vara; the retraction is favourable for the latter, since it allows him to maintain his sub-standpoint without the need to defend it.

The analysis of the accusation as an instance of strategic manoeuvring is enhanced by the knowledge of the rules and conventions of Question Time. The knowledge of institutional rules and conventions and the consequent constraints on the three aspects of strategic manoeuvring is insightful for a good understanding of how arguers actually exploit the opportunities allowed to them in a specific institutional context, in order to steer the discussion towards a favourable outcome. For example, the Member of Parliament in the exchange at hand exploits the choices of presentation defined by the rules and conventions of Question Time, to his own advantage. Restricted by institutional rules, Mr. Vara has to present his argument indirectly in the form of a question. From the range of types of questions allowed to Mr. Vara, he chooses to imply his argument in a yes/no question concerning whether or not the Prime Minister believes that an inconsistency is acceptable. The choice furthers the case of the Member of Parliament since whatever straightforward answer the Prime Minister gives he will be bound to admit the alleged inconsistency. In fact, the Prime Minister attempts to evade such trap, as he responds by saying I would have to look into that fairly carefully before I agreed with the premise behind the hon. Gentleman's question, if I may say so.

The accusation employed by Mr. Vara exhibits also an expedient choice from the topical potential available to him, given the restrictions imposed by institutional rules and conventions on the arguer's concrete moves. The rules of Question Time restrict the institutionally relevant topical potential to the issues for which the Prime Minister 
is responsible. The Member of Parliament chooses from such topics one that steers the discussion to his advantage. In relation to the crisis in Darfur, the government's position is inconsistent; having his argument based on an issue regarding which the actions of the government are inconsistent with its declared position, Mr. Vara has more chances in getting the Prime Minister acknowledge that the actions of his government are not acceptable. After all, if the Prime Minister wants to maintain the government's words of criticism concerning the Sudanese actions in Darfur, which he does, he has to admit that the actions of the government which are inconsistent with these words are unacceptable. In fact, Mr. Vara supports his attempts to steer the discussion towards this outcome even more by the choice of words he makes as he describes the Sudanese actions in Darfur as the 'Sudanese regime's butchery'. This choice of words makes it is very difficult for the Prime Minister to respond to the charge of inconsistency by withdrawing the government's words, and directs him towards acknowledging that the actions of providing training for the Sudanese military are unacceptable instead.

\section{Conclusion}

In this paper, I have attempted to explore the potential contribution of different pragma-dialectical tools and concepts to the integration of institutional insights into the analysis of institutionalised argumentative exchanges. I discussed the concepts of strategic manoeuvring and argumentative activity types and the tool of dialectical profile in light of such contribution. With examples from the argumentative practice of Prime Minister's Question Time, I have shown how these concepts can give account to significant institutional characteristics of argumentative practice.

The concept of argumentative activity types provides the perspective from which institutionalised argumentative exchanges are analysed. As argumentative activity types define and characterise institutionalised argumentative practices, they highlight the role that critical testing plays in achieving institutional aims, and thus, provide a perspective in which a pragma-dialectical examination of such practice makes sense. They further guide the analyst in interpreting the argumentative exchanges that occur as part of this practice and reconstruct them in terms of a critical discussion. That is crucial, because based on it the main standpoints, types of disputes and the roles assumed by the discussants which are specific to a particular institution are identified.

The concept of strategic manoeuvring provides the perspective from which argumentative moves can be analysed. In light of the concept, every argumentative move is an instance of strategic manoeuvring in which an analytically relevant move is realised by making some choice of topics, audience frames and stylistic presentational devices. While dialectical profiles specify what the analytically relevant moves in a certain discussion stage are, institutional rules and conventions determine the allowable topics, audience frames and stylistic presentation for realising such moves as part of a particular activity type. Because dialectical profiles also highlight the role that a particular argumentative move plays in the course of critical testing, the combined knowledge of dialectical profiles and institutional 
rules and conventions sheds significant light on the strategic function that a particular manifestation of strategic manoeuvring has.

Acknowledgement I would like to thank Erik Krabbe for helpful comments on an earlier version of this paper.

Open Access This article is distributed under the terms of the Creative Commons Attribution Noncommercial License which permits any noncommercial use, distribution, and reproduction in any medium, provided the original author(s) and source are credited.

\section{References}

Beard, A. 2000. The language of politics. London: Routledge.

Eemeren, F.H. van, and R. Grootendorst. 1984. Speech acts in argumentative discussions: a theoretical model for the analysis of discussions directed towards solving conflicts of opinion. Dordrecht: Fortis Publications.

Eemeren, F.H. van, and R. Grootendorst. 1992. Relevance reviewed: the case of argumentum ad hominem. Argumentation 6: 141-159.

Eemeren, F.H. van, and R. Grootendorst. 2004. A systematic theory of argumentation. The pragmadialectical approach. Cambridge: Cambridge University Press.

Eemeren, F.H. van, R. Grootendorst, S. Jacobs, and S. Jackson. 1993. Reconstructing argumentative discourse. Tuscaloosa, AL: University of Alabama Press.

Eemeren, F.H. van, and P. Houtlosser. 1999. Strategic manoeuvring in argumentative discourse. Discourse Studies 1(4): 479-497.

Eemeren, F.H. van, and P. Houtlosser. 2002. Strategic maneuvering in argumentative discourse: A delicate balance. In Dialectic and rhetoric: The warp and woof of argumentation analysis, ed. F.H. van Eemeren and P. Houtlosser, 131-159. Dordrecht: Kluwer Academic.

Eemeren, F.H. van, and P. Houtlosser. 2003. The development of the pragma-dialectical approach to argumentation. Argumentation 17(4): 387-403.

Eemeren, F.H. van, and P. Houtlosser. 2005. Theoretical construction and argumentative reality: An analytic model of critical discussion and conventionalised types of argumentative activity. In The uses of argument: Proceedings of a conference at McMaster University, ed. D. Hitchcock, 75-84. Hamilton, Ontario: Ontario Society for the Study of Argumentation.

Eemeren, F.H. van, and P. Houtlosser. 2007a. Seizing the occasion: Parameters for analysing ways of strategic maneuvering. In Proceedings of the sixth conference of the international society for the study of argumentation, ed. F.H. van Eemeren, J.A. Blair, Ch.A. Willard, and B. Garssen, 975-982. Amsterdam: Sic Sat.

Eemeren, F.H. van, and P. Houtlosser. 2007b. Kinship: The relationship between Johnstone's ideas about philosophical argument and the pragma-dialectical theory of argumentation. Philosophy \& Rhetoric 40(1): 51-70.

Eemeren, F.H. van, and P. Houtlosser. 2007c. The study of argumentation as normative pragmatics. Pragmatics and Cognition 15(1): 161-177.

Eemeren, F.H. van, P. Houtlosser, and A.F. Snoeck Henkemans. 2007a. Argumentative indicators in discourse. A pragma-dialectical study. Dordrecht: Springer.

Eemeren, F.H. van, P. Houtlosser, and A.F. Snoeck Henkemans. 2007b. Dialectical profiles and indicators of argumentative moves. In Dissensus and the search for common ground. Proceedings of the OSSA conference 2007 [CD-ROM], ed. H.V. Hansen, C.W. Tindale, R.H. Johnson, and J.A. Blair. Windsor, ON: OSSA.

House of Commons Information Office. 2005. Parliamentary Questions. Factsheet 1. Retrieved January 30, 2007, from http://www.parliament.uk/documents/upload/p01.pdf.

Levinson, S.C. 1979. Activity types and language. Linguistics 17(5): 365-399.

Levinson, S.C. 1992. Activity types and language. In Talk at work: Interaction in institutional settings, ed. P. Drew and J. Heritage, 66-100. Cambridge: Cambridge University Press. 
Mohammed, D. 2007. Argumentative activity types and the account of arguers' empirical aims. In Dissensus and the search for common ground. Proceedings of the OSSA conference 2007 [CDROM], ed. H.V. Hansen, C.W. Tindale, R.H. Johnson, and J.A. Blair. Windsor, ON: OSSA.

Parliamentary Archives. 2006. HC/OF/448/182/1382-4. Retrieved September 10, 2006, from http://www.publications.parliament.uk/pa/cm200506/cmhansrd/cm060712/debtext/60712-0885.htm.

Parliamentary Archives. 2007. HC/OF/461/104/756. Retrieved September 15, 2007, from http://www.publications.parliament.uk/pa/cm200607/cmhansrd/cm070613/debtext/70613-0003.htm.

Rogers, R., and R. Walter. 2006. How parliament works. Harlow, England: Pearson Education Limited. Wilson, J. 1990. Politically speaking: The pragmatic analysis of political language. Oxford, UK: Basil Blackwell. 